\title{
A Review of Relationship between Fear Avoidance Beliefs and Postural Stability in Non Specific Chronic Low Back Pain
}

\section{Abdolkarim Karimi ${ }^{1}$ and Marzieh Saeidi ${ }^{2 *}$}

${ }^{1}$ Assistant Professor, School of Rehabilitation, Isfahan University of Medical Sciences, Iran

${ }^{2}$ Physiotherapist of Shariati Hospital, Management Treatment of Isfahan social security organization, Iran

\begin{abstract}
Introduction: Low back pain (LBP) is one of the most prevalent diseases in most developed and developing countries, affecting $70 \%$ to $80 \%$ of adults at some time during their lives. Recent evidence suggests that psychosocial factors especially fear-avoidance beliefs $(F A B)$ are important in predicting patients who will progress from an acute to a chronic stage as well as failure of interventions. The aim of this study is to review the Relationship between Fear Avoidance Beliefs and Postural stability in non specific Chronic Low Back Pain (CLBP).
\end{abstract}

Methods: In this narrative article we have searched PubMed, CINHAL, APTA and MEDLINE data bases. The key words included: chronic low back pain, fear avoidance beliefs, posture, stability, balance, motor control, center of pressure and force plate. The inclusion criteria were being related to FAB and postural stability and adults with non specific CLBP, in English language, up to 2013, regardless of their study design.

Results: The results showed that psychological factors such as FAB influence the chronicity of LBP, a group of studies indicated that FAB is related to pain and disability. Another group of studies indicated that postural stability is related to pain and disability. The only study on the relationship between postural stability and FAB did not found any significant relationship.

Conclusion: FAB is related to pain and disability. Postural stability is related to pain and disability. More studies with stronger methodology such as larger population with control group are needed for evaluating the relationship of $\mathrm{FAB}$ and postural control.

Keywords: Chronic low back pain; Fear avoidance beliefs; Stability; Motor control

\section{Introduction}

Low back pain (LBP) is one of the most common health problems which affect $60 \%$ to $80 \%$ of adults at some time during their lives [1,2]. About $85 \%$ of patients with back pain are classified as non specific chronic low back pain [3]. Although most of the time, LBP is a selflimiting disorder and a majority of these patients will improve rapidly [4], half of them has a long history of multiple episodes [5] and in a small group of them (about10\%), pain will become chronic [6-8]. This group of patients allocate about $80 \%$ of costs to themselves [9]. Consequently, LBP is a major public health problem with an immense socioeconomic burden in most developed and developing countries.

Studies on patients with acute or sub acute LBP reveal several factors influence on progression to chronicity of LBP such as: high level of psychological distress, dissatisfaction with employment, longer duration of symptoms, previous history of LBP, radiating pain and higher initial disability level [10-13], psychosocial factors like the patients attitudes and beliefs, pain and movement related fear, stress, depression, job satisfaction, self confidence and self assurance are very important in CLBP $[14,15]$. The cognitive-behavior concept of developing chronic pain is appearing as fear-avoidance behavior at early stage. Cox et al. explained in a model the reason of pain exaggeration and the reason of developing pain in to chronic stage in some of the patients while improving in others [16]. According to this model, the patient's fear of pain, and subsequent avoidance behavior, are determined by the relation between sensory and emotional components of pain. The hypothesis is that the patients believes and fears concerning symptoms and activity lead to unhelpful ways of managing symptoms, including avoidance behaviors, decreasing activities of daily living, job and recreation which reflect a state of not feeling well. Also failing to diagnose factors which influence their condition can lead to use an inappropriate treatment approach.
In individuals with LBP, the Fear-Avoidance Belief Questionnaire (FABQ) quantifies pain-related fears and believes about the necessity of changing the behavior of pain avoidance [17]. Pain related fear refers to a condition in which the patient has an excessive, irrational, and debilitating fear of physical movement and activity, resulting in feelings of vulnerability to painful injury or re-injury $[18,19]$. Biomechanical factors such as strength or endurance, flexibility spinal stability and neurophysiologic factors have been studied in several investigations [20-22]. It is important for physicians and physiotherapists to have enough information in this area in order to be able to recognize the obstacles of the patients' improvement and adopt an appropriate strategy accordingly.

Optimal postural control is an essential requirement to perform daily activities. Postural stability is a component of postural balance which indicates the ability of maintaining a certain posture and is described by center of pressure (COP) excursion $[23,24]$. Many factors may contribute to control postural stability including age, neurological or musculoskeletal disorders such as LBP and biomechanical factors such as muscle endurance $[21,25]$. The influence of LBP on postural balance is complex and affected by co-existing factors: pain, fear of pain, positive neurologic findings, adoption of an alternate movement strategy, and low muscular conditioning [24,26-30]. Several studies

*Corresponding author: Marzieh Saeidi, Physiotherapist of Shariati Hospital, Management Treatment of Isfahan Social Security Organization, Iran, E-mail: pt_msaeidi@yahoo.com

Received April 30, 2013; Accepted July 08, 2013; Published July 10, 2013

Citation: Karimi A, Saeidi M (2013) A Review of Relationship between Fear Avoidance Beliefs and Postural Stability in Non Specific Chronic Low Back Pain. J Spine 2: 139. doi:10.4172/2165-7939.1000139

Copyright: @ 2013 Karimi A, et al. This is an open-access article distributed under the terms of the Creative Commons Attribution License, which permits unrestricted use, distribution, and reproduction in any medium, provided the original author and source are credited. 
have shown that patients with CLBP have some problems for postural control [31,32]. Fear-avoidance believes have been hypothesized as the most important psychosocial factor in predicting disability and work time loss among patients with chronic low back pain (CLBP). So identifying potentially modifiable determinants of disability in patients with LBP provides an opportunity to expand strategies of controlling socioeconomic problems. Many studies have assessed the relationship of either impairment or psychosocial factors with disability and pain [33-36], but to our knowledge, relationship between the level of FearAvoidance Belief (FAB) and the parameters of postural stability is not well studied and it needs more studies. The aim of this study is reviewing the studies on the relationship between psychosocial factors especially pain related fear with postural stability in non specific chronic low back pain.

\section{Methods}

In this narrative review article the PubMed, CINHAL, APTA and MEDLINE data bases were searched for articles on relationship between pain and pain related fear and postural stability. The related key words included: back pain, chronic low back pain, fear avoidance beliefs, postural stability, postural control, force plate and center of pressure. The criteria for evaluation of the articles were included: their title being related to the topic (defining the relationship between pain related fear, pain, disability, postural stability and postural control), with any design, up to 2013 published in English. Twenty five articles had the inclusion criteria. The studied out comes included activity and reaction time of trunk muscles, center of pressure excursion (sway), fear avoidance beliefs, pain and disability. Studies which did not evaluate the relation of these outcomes were excluded.

\section{Results}

According to the inclusion and exclusion criteria 25 articles were found which met the inclusion and exclusion criteria. These studies were summarized in Table 1 and 2. The studies were divided in 3 categories: studies on relationship between pain, disability and FAB, studies on the relationship between pain, disability and postural stability and studies on relationship between $\mathrm{FAB}$ and postural stability.

\section{Pain, disability and fear avoidance beliefs}

Psychological factors may be related to the onset, development, and treatment outcome of spinal pain. Strong evidence also shows that psychosocial variables generally influence more than biomedical or biomechanical factors on chronic back pain [37-43]. Recent evidence suggests that psychosocial factors are important in predicting patients who will progress from an acute to a chronic stage as well as failure of interventions $[13,14]$. Patients with chronic pain often demonstrate anxiety and depression [15].

Several studies have shown the relationship between pain, FAB and disability in patients with CLBP [38-43]. With regard to psychosocial factors, a growing body of published data has provided evidence that elevated pain-related fear predicted disability in patients with acute and chronic LBP [35,41-43]. People who experience pain-related fear will avoid activities they associate with increased risk for pain or (re) injury $[18,19]$. Therfore pain-related fear have a negative impact on the results of performance testing $[35,44]$. Correlation analysis in a study by Guclu indicated a significant but positive weak association between the severity of pain and fear avoidance (physical, work and overall) [45]. The relation between pain, pain related fear and functional performance is weak or non-existent in patients with CLBP [46]. A hospital casecontrol study in Iran, compared the psychological features in patients with low-back pain. Patients' levels of depression and anxiety were related to occupational background. Longer duration of illness was also accompanied by higher levels of anxiety and depression [33]. Another study indicated that Pain was positively related with fear-avoidance beliefs, catastrophizing, and anxiety. In addition, job had a moderating effect on the relationship between pain and anxiety so that job indicated $24.6 \%$ of pain variance [47]. Two review articles by Leeuw [48] and Akhbari [49] indicated that there is a positive relationship between

\begin{tabular}{|c|c|c|c|}
\hline Author & Study design & Topic & Results \\
\hline Lafond et al. [32] & Case-control & $\begin{array}{l}\text { Postural balance during prolong } \\
\text { standing in low back pain patients }\end{array}$ & Decreasing of Cop velocity, frequency and excursion \\
\hline Della Volpe et al. [58] & Case-control & $\begin{array}{l}\text { Postural control during dynamic } \\
\text { standing in low back pain patients }\end{array}$ & Increasing of Cop excursion \\
\hline Luoto et al. [33] & $\begin{array}{c}\mathrm{RCT} \\
\mathrm{n}=99(\mathrm{LBP}), \mathrm{n}=61 \text { (Healthy) }\end{array}$ & Reaction time and COP velocity & $\begin{array}{l}\text { Postural control was weaker in CLBP and improved after } \\
\text { rehabilitation }\end{array}$ \\
\hline Mann et al. [24] & Case-control & Postural control in CLBP & Cop velocity was higher in CLBP \\
\hline Brumagne et al. [26] & $\begin{array}{l}\text { Case-control, } n=52(\text { LBP), } \\
n=33 \text { (Healthy) }\end{array}$ & Postural control in CLBP & Cop excursion was higher in CLBP \\
\hline $\begin{array}{l}\text { Brumagne et al. } \\
\qquad[54]\end{array}$ & $\begin{array}{l}\text { Case-control, } n=21(\text { LBP }) \text {, } \\
n=24(\text { Healthy) }\end{array}$ & $\begin{array}{l}\text { Postural stability and postural control } \\
\text { strategy in persons with recurrent LBP }\end{array}$ & $\begin{array}{l}\text { persons with recurrent LBP use the same postural control } \\
\text { strategy even in standing on an unstable support surface }\end{array}$ \\
\hline Ruhe et al. [27] & Systematic review & Postural control in CLBP & $\begin{array}{l}\text { Cop velocity and excursion were related to LBP but not pain } \\
\text { intensity }\end{array}$ \\
\hline Ruhe et al. [60] & $\begin{array}{c}\text { Case-control, } \\
\mathrm{n}=77(\mathrm{LBP}), \mathrm{n}=77 \text { (Healthy) }\end{array}$ & $\begin{array}{l}\text { Is there a relationship between pain } \\
\text { intensity and } \\
\text { postural sway in patients with CLBP }\end{array}$ & $\begin{array}{l}\text { COP mean velocity and sway area are closely related to self- } \\
\text { reported pain scores. }\end{array}$ \\
\hline Ruhe et al. [61] & $\begin{array}{l}\text { Case-control, } \\
\mathrm{n}=38 \text { (LBP), } \mathrm{n}=38 \text { (Healthy) }\end{array}$ & $\begin{array}{l}\text { Pain relief is associated with } \\
\text { decreasing postural } \\
\text { sway in patients with CLBP }\end{array}$ & $\begin{array}{l}\text { Alterations in pain intensities are closely related to changes in } \\
\text { postural sway. }\end{array}$ \\
\hline Takala and Juntura [28] & Cohort, two year follow up, $n=430$ & $\begin{array}{l}\text { Role of functional tests in prediction } \\
\text { of LBP }\end{array}$ & Weak performance was related to low stability and endurance \\
\hline Moseley et al. [30] & Comparative before and after, $n=16$ & $\begin{array}{l}\text { Relationship between experimental } \\
\text { pain and Postural control in CLBP }\end{array}$ & Pain causes delay in postural muscle activation \\
\hline Mazaheri et al. [57] & systematic review & $\begin{array}{l}\text { postural sway during quiet standing } \\
\text { in LBP }\end{array}$ & $\begin{array}{c}\text { Most studies reported an increased postural sway in LBP or no } \\
\text { effect of LBP on postural sway. }\end{array}$ \\
\hline
\end{tabular}

Table 1: Studies on Postural control, pain and disability. 


\begin{tabular}{|c|c|c|c|}
\hline Author & Study design & Topic & Results \\
\hline Crombez et al. [41] & Cross sectional, $n=124$ & $\begin{array}{l}\text { Relationship between pain and fear of pain } \\
\text { with disability in CLBP }\end{array}$ & Pain is related to FAB and disability \\
\hline Klenerman et al. [42] & Cohort, one year follow up, & $\begin{array}{c}\text { Role of fear avoidance beliefs in prediction } \\
\text { of LBP }\end{array}$ & $7 \%$ become chronic ( $66 \%$ due to fear of pain) \\
\hline Afshar Neghad et al. [64] & Cross sectional $n=50$ & $\begin{array}{l}\text { Relation between fear of movement, pain } \\
\text { and disability in chronic low back pain }\end{array}$ & $\begin{array}{l}\text { fear of movement, pain intensity and age are } \\
\text { related to disability }\end{array}$ \\
\hline Akhbari et al. [49] & review & $\begin{array}{l}\text { The Fear of Movement/Pain in } \\
\text { Musculoskeletal Pain-A Review }\end{array}$ & fear of pain can be as disabling as pain itself \\
\hline Gatchel et al. [14] & Cohort, one year follow up, $n=221$ & Role of psychological factors in CLBP & $\begin{array}{l}\text { High prevalence of psychological diseases in } \\
\text { CLBP }\end{array}$ \\
\hline Linton [15] & Systematic review & $\begin{array}{c}\text { Role of psychological factors in CLBP and } \\
\text { neck pain }\end{array}$ & $\begin{array}{c}\text { clear link between psychological variables and } \\
\text { neck and back pain onset }\end{array}$ \\
\hline Sajjadian et al. [47] & Cross sectional $n=50$ & $\begin{array}{l}\text { fear-avoidance believes, pain } \\
\text { catastrophizing and anxiety effects on } \\
\text { chronic low back pain in women }\end{array}$ & $\begin{array}{l}\text { Chronic low back pain can be predicted by } \\
\text { fear-avoidance beliefs and catastrophizing }\end{array}$ \\
\hline Guclu et al. [45] & Cross sectional $n=105$ & $\begin{array}{l}\text { The Relationship Between Disability, } \\
\text { Quality of Life } \\
\text { and Fear-Avoidance Beliefs in CLBP }\end{array}$ & $\begin{array}{l}\text { Higher levels of anxiety, depression, FABQ } \\
\text { (work) leads to higher level of disability }\end{array}$ \\
\hline Ramond et al. [38] & systematic review & $\begin{array}{l}\text { Psychosocial risk factors for chronic low } \\
\text { back pain in } \\
\text { primary care }\end{array}$ & $\begin{array}{c}\text { Depression,psychological distress, passive } \\
\text { coping } \\
\text { strategies and FAB were independently linked } \\
\text { with poor outcome }\end{array}$ \\
\hline Leeuw et al. [47] & Review Paper & $\begin{array}{l}\text { The Fear-Avoidance Model of } \\
\text { Musculoskeletal Pain: Current State of } \\
\text { Scientific Evidence }\end{array}$ & $\begin{array}{c}\text { pain-related fear is associated with catastrophic } \\
\text { interpretations of pain, avoidance behaviors, } \\
\text { pain intensity and disability }\end{array}$ \\
\hline Davis et al. [62] & Cross sectional $n=235$ & $\begin{array}{c}\text { Variables Associated With Level of } \\
\text { Disability }\end{array}$ & $\begin{array}{l}\text { Disability is related to duration of LBP, higher } \\
\text { level of pain intensity and FAB, and stability } \\
\text { (velocity in the forward direction }\end{array}$ \\
\hline Maribo et al. [43] & Validity, $n=97$ & Postural balance in low back pain patients & $\begin{array}{l}\text { No relationship between pain, FAB and COP } \\
\text { excursion }\end{array}$ \\
\hline Lamoth et al. [32] & Case-control & $\begin{array}{l}\text { Relationship between pain and fear of pain } \\
\text { with muscle coordination in CLBP }\end{array}$ & $\begin{array}{l}\text { Pain intensity, kinsiophobia and disability were } \\
\text { not related to postural muscle function but were } \\
\text { due to LBP }\end{array}$ \\
\hline
\end{tabular}

Table 2: Studies on pain and fear of pain and disability and postural control.

pain-related fear, pain intensity and disability; in addition, pain-related fear results in poor clinical outcomes.

\section{Pain, disability and postural stability}

Several studies have shown that postural control parameters change in CLBP however, there is controversy on relationship between pain and postural control parameters, $[32,37,50-56]$ so that some of them indicated increasing postural sway [53], others have shown decreasing postural sway [51] while in the other studies, there was not any significant relationship between pain intensity and postural sway [54]. Of course one of the two recent systematic review article has revealed that pain results in enhancement of cop excursion [27] while the other systematic review indicated that there is equal number of studies showing increased sway in LBP, or no effect of LBP on sway [57].

In LBP patients, delayed contraction of trunk muscles, which results in reduced stiffness of the spine at the time of initiation of the movement, occurs when the equilibrium of the spine is disturbed by rapid movements of the upper or lower limbs [51,52]. In recent years, it has become evident that muscle pain can interfere with motor control strategies and different patterns of interaction are seen during rest, static contractions, and dynamic conditions [51].

Altered postural adjustments of the trunk muscles during pain are not caused by pain interference but are likely to reflect development and adoption of an alternate postural adjustment strategy [30]. Although postural activation of the deep trunk muscles is not affected when central nervous system resources are limited, it is delayed when the individual is also under stress $[57,58]$.
In CLBP patients, postural stability under challenging conditions such as prolonged standing is maintained by an increased sway in anterior-posterior direction. This alteration in postural strategy may provide a dysfunction of the peripheral proprioceptive system or the central integration of proprioceptive information [59]. These findings point to possible neurophysiologic mechanisms that could help explaining why fear of pain is a strong predictor of pain-related disability [60] (Table 2).

Another study in 2011 has shown postural stability is related to higher level of pain intensity and lower level of pain intensity don't due to alteration of postural stability [61]. A new study showed that disability is related to duration of LBP, higher level of pain intensity, FAB and stability (velocity in the forward direction) [62].

\section{Studies on relationship between FAB and postural stability}

The only study of concurrent and predictive validity of postural balance in LBP patients did not found any significant relationship between fear avoidance beliefs and postural stability (COP excursion and velocity) [50]. Baseline and 12-week follow-up results of 97 LBP patients were evaluated. The correlations between $\mathrm{CoP}$ measurements and pain, fear of pain, and physical function were poor. There were no significant differences in CoP measurements between patients with no change or deterioration and patients with improvement in pain and back-specific function [50]. Also another study has evaluated the relationship between kinesiophobia and trunk muscles function but they were not related significantly [32]. Correlation analysis in a study by Kusters showed that neither fear of movement and catastrophizing nor pain was related to either reaction time (RT) or movement time (MT) [63]. Another study by Afshar-nezhad also indicated that fear 
of movement; pain intensity and age are related to disability [64]. Guclu showed that when fear-avoidance (physical, work and overal), increased, disability increased as well [45]. In the study of Crombez et al. [65] a moderately significant relation was found between physical and work fear-avoidance behavior and disability.

\section{Discussion}

The aim of this study was to review the relationship between psychological factors focusing on FAB, pain, disability and postural stability.

According to the results, first group of studies showed that psychological factors such as FAB influence the chronicity of LBP; in addition FAB is related to pain and disability.

Another group indicated that postural stability is related to pain and disability. Also a few studies indicated that FAB is related to postural stability in subjects without CLBP but only one study has investigated this relationship in patients with CLBP in which there was not seen any significant relationship between FAB and postural stability.

Sajjadian et al. showed that Pain was positively related to fearavoidance beliefs, catastrophizing, and anxiety [47]. In her study, fearavoidance beliefs and catastrophizing explained $45.6 \%$ of the variance of the pain. In addition, she revealed that job had a moderating effect on the relationship between anxiety and pain. Her study carried out on women who reported higher level of FAB compared to men [47]. Sions and Hicks [66] explained the lack of a significant relation between fear avoidance and disability in their Hispanic patients, in these patients. It seems that pain intensity and ethnic characteristics are underlying factor for this controversy. Hicks et al stated that fear and avoidance behavior in work is a highly specific finding for disability [67]. George et al. [68] demonstrated that in patients with chronic low back pain, the single predictor of disability was fear avoidance behavior (work). As to the study of Waddell et al. [17], severity of pain and fear avoidance behavior was found to be predictors of disability [17]. The relationship between pain related fear and performance appeared stronger in studies where patients were observed under strictly controlled conditions, and weaker in studies where patients were observed in a less controlled environment $[41,69]$. However the relationship between pain, fear avoidance beliefs and postural stability was different in these studies. According to the study by Isableu and Vuillerme [70] in quiet standing, postural sway will decrease because of trunk stiffening strategy or ankle strategy but during standing on foam, postural stability will decrease in patients with CLBP compared to healthy subjects; while in another study by Brumagne et al. [54], the results showed that in both quiet standing in a stable surface and unstable surface (foam) is different in patients with CLBP compared to healthy subjects. These results support the hypothesis that in more complex postural conditions postural stability decrease in persons with LBP compared to healthy controls. Ruhe et al. demonstrated a linear relationship between pain intensity and postural sway velocities in both sagital and frontal plans [60], however, the sway velocity in frontal plan increased at a faster rate. In addition, his study confirms the altered postural sway characteristics previously reported in a systematic review of NSLBP sufferers [27]. The most important finding of his study was that higher intensity of pain perception is related to COP measurements which can describe why in some studies pain intensity was not related to the postural stability. Therefore the neurological alteration previously described [30,71-74] may only have an impact on COP measures at medium to high intensities (more than 5 in numeric rating scale of pain). These results are in agreement with observations of Lihavainen et al. [75] who conducted a similar study in a geriatric population, of course, pain was measured based on a subdivision into mild or moderate/ severe pain only in their study and the studied population was different characteristically. However, according to using a protocol based on best evidence [60], future studies are not needed to confirm these findings using the same protocol. Considering the inclusion criteria, focusing on those with higher pain intensity to reach significance compared to controls more readily, the results may also interpret the results of studies (e.g. Brumange et al. [54] and Mok et al. [29]), in which there were not significant differences in postural sway between symptomatic individuals and healthy controls because of low pain intensities of the NSLBP participants enrolled. There is evidence that higher COP sway is associated with a higher risk of falling in the elderly [76] therefore the importance of suitable pain control in elderly pain sufferers to avoid falls. Furthermore, as pain interference appears a likely underlying mechanism, the focus of a rehabilitative approach in pain sufferers with increased COP excursions should be on pain reduction rather than proprioceptive training.

As the lower back motor tasks are often considered both painful and threatening by patients, it is hard to distinguish whether performance insufficiency is attributed to pain experience or to pain related cognitions. Only a few studies tried to enable analysis of pain effect apart from cognition effect. Lamoth et al. studied the influence of both parameters (pain and fear of pain) on gait in healthy subjects [77]. Their results show that only pain influenced on gait parameters. Considering subjects awareness of disappearing pain eventually, painrelated fear may not be representative for this population since pain is present continuously and pain-related fear is much more substantial. Kasters [63] and Luoto [33] indicated slower reaction time of patients compared to healthy subjects concluded that the reaction time in CLBP patients was not influenced by cognitions. The contradiction of their studies with findings of previous studies demonstrating a deteriorating role for pain-related cognitions and reaction time performance $[64,78,79]$ may be due to differences in experimental design (i.e. different reaction time tasks).

In sum, there is lack of knowledge concerning the relation between pain, pain-related cognitions and deviations in CLBP patients' motor performance. As it is conceivable that managing pain demands a different treatment approach than managing pain-related cognitions, this knowledge might be useful to increase CLBP therapy effectiveness.

The only recent study of concurrent and predictive validity of postural balance in LBP patients revealed no association between COP measures and pain, fear of pain, and physical function. According to recommendations for COP measures were published in 2010 in order to reduce measurement errors, this recent study may have some errors such as being included all low back patients, not considering age groups and procedure of measuring COP (60 second sampling duration instead of 90 second and 2 trials instead of 3-5 trials) [27,61].

Also, a high level of anxiety increased postural sway in healthy individuals, with an increment of path length in the anteroposterior axis [80]. On the other hand, Lopes found a significantly reduced body sway area and mean power frequency thorough the experiment as well as a negative correlation between anticipatory anxiety and mean sway area when compared to control participants [81]. Levitan et al. also found that patients with social anxiety disorder showed a reduced sway area and a lower velocity in the mediolateral direction during presentation of all blocks of pictures compared to control [80]. His study showed that body sway in patients with social anxiety disorder is smaller than in controls independently of the presence and contents of visual information maybe because the stimulus of anxiety was not enough [80]. 
To become a short story, it seems that different results of the evaluated studies are due to the way of data collection, population characteristics (physical activity and fitness level and age), inclusion/ exclusion criteria, the level of pain, postural stability and fear avoidance beliefs at the beginning of the studies. Also different instruments (the questionnaires and scales for fear avoidance, pain, force plates), different procedures of measuring postural stability (quiet standing or single leg stand or sitting, with open or closed eye and the position of the hands the number of trials, frequency of filtering and capturing) and different outcome measures for postural stability (muscle activity, reaction time, COP displacement, velocity, mean frequency) used in these studies can be consider for variability of their results.

\section{Conclusion}

It can be concluded that pain related fear may be one of the factors of failure the treatments of patients with NCLBP. FAB is related to pain and disability. Postural stability is related to pain and disability. More exact studies are needed for evaluating the relationship of FAB and postural control.

\section{Limitations}

One of the most important limitations of this study is lack of the statistical analysis and criterion evaluation of the included studies.

\section{Suggestions}

It is recommended to evaluate more similar and related studies from other data bases which focus on the topic according to their power as well as using statistical analysis of their data where it is possible.

\section{References}

1. Deyo RA, Weinstein JN (2001) Low back pain. N Engl J Med 344: 363-370.

2. O'Sullivan P (2005) Diagnosis and classification of chronic low back pain disorders: maladaptive movement and motor control impairments as underlying mechanism. Man Ther 10: 242-255.

3. Deyo RA, Phillips WR (1996) Low back pain. A primary care challenge. Spine (Phila Pa 1976) 21: 2826-2832.

4. Pengel LH, Herbert RD, Maher CG, Refshauge KM (2003) Acute low back pain: systematic review of its prognosis. BMJ 327: 323.

5. Raspe HH (1993) Back pain. In: Silman AJ, Hochberg MC, editors. Epidemiology of the Rheumatic Diseases. Oxford: Oxford University Press.

6. Carey TS, Garrett JM, Jackman AM (2000) Beyond the good prognosis. Examination of an inception cohort of patients with chronic low back pain. Spine (Phila Pa 1976) 25: 115-120.

7. Balagué $F$, Mannion AF, Pellisé F, Cedraschi C (2012) Non-specific low back pain. Lancet 379: 482-491.

8. van den Hoogen HJ, Koes BW, van Eijk JT, Bouter LM, Devillé W (1998) On the course of low back pain in general practice: a one year follow up study. Ann Rheum Dis 57: 13-19.

9. Waddell G (2004) The back pain revolution. Edinburgh, UK: Churchill Livingstone.

10. Main CJ, Watson PJ (1999) Psychological aspects of pain. Man Ther 4: 203215

11. Burton AK, Tillotson KM, Main CJ, Hollis S (1995) Psychosocial predictors of outcome in acute and subchronic low back trouble. Spine (Phila Pa 1976) 20: 722-728.

12. Thomas E, Silman AJ, Croft PR, Papageorgiou AC, Jayson MI, et al. (1999) Predicting who develops chronic low back pain in primary care: a prospective study. BMJ 318: 1662-1667.

13. van den Hoogen HJ, Koes BW, Devillé W, van Eijk JT, Bouter LM (1997) The prognosis of low back pain in general practice. Spine (Phila Pa 1976) 22: 15151521.
14. Gatchel RJ, Polatin PB, Mayer TG (1995) The dominant role of psychosocial risk factors in the development of chronic low back pain disability. Spine (Phila Pa 1976) 20: 2702-2709.

15. Linton S (2000) Psychological risk factors for neck and back pain. In: A Nachemson and E. Jonsson (Eds.), Neck and back pain: The scientific evidence of causes, diagnosis, and treatment. Lippincott Williams \& Wil-kins, Philadelphia

16. Cox ME, Asselin S, Gracovetsky SA, Richards MP, Newman NM, et al. (2000) Relationship between functional evaluation measures and self-assessment in nonacute low back pain. Spine (Phila Pa 1976) 25: 1817-1826.

17. Waddell G, Newton M, Henderson I, Somerville D, Main CJ (1993) A FearAvoidance Beliefs Questionnaire (FABQ) and the role of fear-avoidance beliefs in chronic low back pain and disability. Pain 52: 157-168.

18. Kori SH, Miller RP, Todd DD (1990) Kinesiophobia: a new view of chronic pain behavior. Pain Manage 35-43.

19. Vlaeyen JW, Kole-Snijders AM, Boeren RG, van Eek H (1995) Fear of movement/(re)injury in chronic low back pain and its relation to behavioral performance. Pain 62: 363-372.

20. Lund T (2003) Biomechanical aspects of chronic low back pain: Kinematics and stabilization,Orton Orthopaedic Hospital, Invalid Foundation, University of Helsinki, Helsinki.

21. Nourbakhsh MR, Arab AM (2002) Relationship between mechanical factors and incidence of low back pain. J Orthop Sports Phys Ther 32: 447-460.

22. Nourbakhsh MR, ArablooAM, Salavati M (2006) The relationship between pelvic cross syndrome and chronic low back pain. $\mathrm{J}$ of Back and Musculoskeletal Rehabilitation 19: 119-128.

23. Pollock AS, Durward BR, Rowe PJ, Paul JP (2000) What is balance? Clin Rehabil 14: 402-406.

24. Mann L, Kleinpaul JF, Pereira Moro AR, Mota CB, Carpes FP (2010) Effect of low back pain on postural stability in younger women: influence of visual deprivation. J Bodyw Mov Ther 14: 361-366.

25. Hodges PW, Moseley GL (2003) Pain and motor control of the lumbopelvic region: effect and possible mechanisms. J Electromyogr Kinesiol 13: 361-370.

26. Brumagne S, Janssens L, Janssens E, Goddyn L (2008) Altered postura control in anticipation of postural instability in persons with recurrent low back pain. Gait Posture 28: 657-662.

27. Ruhe A, Fejer R, Walker B (2011) Center of pressure excursion as a measure of balance performance in patients with non-specific low back pain compared to healthy controls: a systematic review of the literature. Eur Spine J 20: 358-368.

28. Takala EP, Viikari-Juntura E (2000) Do functional tests predict low back pain? Spine (Phila Pa 1976) 25: 2126-2132.

29. Mok NW, Brauer SG, Hodges PW (2004) Hip strategy for balance control in quiet standing is reduced in people with low back pain. Spine (Phila Pa 1976) 29: E107-112.

30. Moseley GL, Hodges PW (2005) Are the changes in postural control associated with low back pain caused by pain interference? Clin J Pain 21: 323-329.

31. Lamoth CJ, Meijer OG, Daffertshofer A, Wuisman PI, Beek PJ (2006) Effects of chronic low back pain on trunk coordination and back muscle activity during walking: changes in motor control. Eur Spine J 15: 23-40.

32. Lafond D, Champagne A, Descarreaux M, Dubois JD, Prado JM, et al. (2009) Postural control during prolonged standing in persons with chronic low back pain. Gait Posture 29: 421-427.

33. Luoto S, Taimela S, Hurri H, Aalto H, Pyykkö I, et al. (1996) Psychomotor speed and postural control in chronic low back pain patients A controlled followup study. Spine (Phila Pa 1976) 21: 2621-2627.

34. Al-Obaidi SM, Beattie P, Al-Zoabi B, Al-Wekeel S (2005) The relationship of anticipated pain and fear avoidance beliefs to outcome in patients with chronic low back pain who are not receiving workers' compensation. Spine (Phila Pa 1976) 30: 1051-1057.

35. Vlaeyen JW, Linton SJ (2000) Fear-avoidance and its consequences in chronic musculoskeletal pain: a state of the art. Pain 85: 317-332.

36. Fanian H, Ghassemi GR, Jourkar M, Mallik S, Mousavi MR (2007) Psychological profile of Iranian patients with low-back pain. East Mediterr Health J 13: 335346. 
37. Leinonen V, Kankaanpää M, Hänninen O, Airaksinen O, Taimela S (2002) Paraspinal muscle responses during sudden upper limb loading. Eur $\mathrm{J}$ App Physiol 88: 42-49.

38. Ramond A, Bouton C, Richard I, Roquelaure Y, Baufreton C, et al. (2011) Psychosocial risk factors for chronic low back pain in primary care--a systematic review. Fam Pract 28: 12-21.

39. Sieben JM, Portegijs PJ, Vlaeyen JW, Knottnerus JA (2005) Pain-related fear at the start of a new low back pain episode. Eur J Pain 9: 635-641.

40. Gheldof EL, Vinck J, Van den Bussche E, Vlaeyen JW, Hidding A, et al. (2006) Pain and pain-related fear are associated with functional and social disability in an occupational setting: evidence of mediation by pain-related fear. Eur $J$ Pain 10: 513-525.

41. Crombez G, Vlaeyen JW, Heuts PH, Lysens R (1999) Pain-related fear is more disabling than pain itself: evidence on the role of pain-related fear in chronic back pain disability. Pain 80: 329-339.

42. Klenerman L, Slade PD, Stanley IM, Pennie B, Reilly JP, et al. (1995) The prediction of chronicity in patients with an acute attack of low back pain in a general practice setting. Spine (Phila Pa 1976) 20: 478-484

43. George SZ (2006) Fear: a factor to consider in musculoskeletal rehabilitation. $J$ Orthop Sports Phys Ther 36: 264-266.

44. Geisser ME, Robinson ME, Miller QL, Bade SM (2003) Psychosocial factors and functional capacity evaluation among persons with chronic pain. J Occup Rehabil 13: 259-276.

45. Guclu DG, Guclu O, Ozaner A, Senormanci O, Konkan R (2012) The relationship between disability, quality of life and fear-avoidance beliefs in patients with chronic low back pain. Turk Neurosurg 22: 724-731.

46. Brox JI, Storheim K, Holm I, Friis A, Reikerås O (2005) Disability, pain psychological factors and physical performance in healthy controls, patients with sub-acute and chronic low back pain: a case-control study. J Rehabil Med 37: 95-99.

47. Sajjadian I, Neshat Dost HT, Molavi H, Bagherian-Sararoudi HR (2012) Cognitive and emotional factors effective on chronic low back pain in women: Explanation the role of fear-avoidance believes, pain catastrophizing and anxiety. Journal of Behavioral Sciences investigation 9: 305-316.

48. Leeuw M, Goossens ME, Linton SJ, Crombez G, Boersma K, et al. (2007) The fear-avoidance model of musculoskeletal pain: current state of scientific evidence. J Behav Med 30: 77-94.

49. Akhbari B, MohammadiRad S., Salavati M (2012) The Fear of Movement/Pain in Musculoskeletal Pain-A Review. Journal of rehabilitation 2012 13: 84-92.

50. Maribo T, Schiøttz-Christensen B, Jensen LD, Andersen NT, StengaardPedersen K (2012) Postural balance in low back pain patients: criterion-related validity of centre of pressure assessed on a portable force platform. Eur Spine J 21: 425-431

51. Hodges PW, Richardson CA (1996) Inefficient muscular stabilization of the lumbar spine associated with low back pain. A motor control evaluation of transversus abdominis. Spine (Phila Pa 1976) 21: 2640-2650.

52. Hodges PW, Richardson CA (1998) Delayed postural contraction of transversus abdominis in low back pain associated with movement of the lower limb. J Spinal Disord 11: 46-56.

53. Arendt-Nielsen L, Graven-Nielsen T (2008) Muscle pain: sensory implications and interaction with motor control. Clin J Pain 24: 291-298.

54. Brumagne S, Janssens L, Knapen S, Claeys K, Suuden-Johanson E (2008) Persons with recurrent low back pain exhibit a rigid postural control strategy. Eur Spine J 17: 1177-1184.

55. Lamoth CJ, Daffertshofer A, Meijer OG, Lorimer Moseley G, Wuisman PI, et al. (2004) Effects of experimentally induced pain and fear of pain on trunk coordination and back muscle activity during walking. Clin Biomech (Bristol, Avon) 19: 551-563.

56. Hodges PW, Moseley GL, Gabrielsson A, Gandevia SC (2003) Experimental muscle pain changes feedforward postural responses of the trunk muscles. Exp Brain Res 151: 262-271.

57. Mazaheri M, Coenen P, Parnianpour M, Kiers H, van Dieën JH (2013) Low back pain and postural sway during quiet standing with and without sensory manipulation: a systematic review. Gait Posture 37: 12-22.

58. della Volpe R, Popa T, Ginanneschi F, Spidalieri R, Mazzocchio R, et al. (2006)
Changes in coordination of postural control during dynamic stance in chronic low back pain patients. Gait Posture 24: 349-355.

59. Sullivan MJ, Thibault P, Andrikonyte J, Butler H, Catchlove R, et al. (2009) Psychological influences on repetition-induced summation of activity-related pain in patients with chronic low back pain. Pain 141: 70-78.

60. Ruhe A, Fejer R, Walker B (2011) Is there a relationship between pain intensity and postural sway in patients with non-specific low back pain? BMC Musculoskeletal Disorders 12: 162.

61. Ruhe A, Fejer R, Walker B (2010) The test-retest reliability of centre of pressure measures in bipedal static task conditions--a systematic review of the literature. Gait Posture 32: 436-445.

62. Davis DS, Mancinelli CA, Petronis JJ, Bensenhaver C, McClintic T, et al. (2013) Variables associated with level of disability in working individuals with nonacute low back pain: a cross-sectional investigation. J Orthop Sports Phys Ther 43 97-104.

63. Kusters D, Vollenbroek-Hutten MM, Hermens HJ (2011) Motor performance in chronic low back pain: is there an influence of pain-related cognitions? A pilot study. BMC Musculoskelet Disord 12: 211

64. Afshar Neghad T, Rezaei S, Yousef zadeh SH (2011) The relation between fear of movement, pain and disability in chronic low back pain. Journal of Rehabilitation 11: 21-28.

65. Crombez G, Hermans D, Adriaensen H (2000) The emotional stroop task and chronic pain: what is threatening for chronic pain sufferers? Eur J Pain 4: 37-44.

66. Sions JM, Hicks GE (2011) Fear-avoidance beliefs are associated with disability in older American adults with low back pain. Phys Ther 91: 525-534.

67. Hicks GE, Fritz JM, Delitto A, McGill SM (2005) Preliminary development of a clinical prediction rule for determining which patients with low back pain wil respond to a stabilization exercise program. Arch Phys Med Rehabil 86: 1753 1762.

68. George SZ, Fritz JM, Childs JD (2008) Investigation of elevated fear-avoidance beliefs for patients with low back pain: a secondary analysis involving patients enrolled in physical therapy clinical trials. J Orthop Sports Phys Ther 38: 50-58.

69. Verbunt JA, Westerterp KR, van der Heijden GJ, Seelen HA, Vlaeyen JW, et al. (2001) Physical activity in daily life in patients with chronic low back pain. Arch Phys Med Rehabil 82: 726-730.

70. Isableu B, Vuillerme N (2006) Differential integration of kinaesthetic signals to postural control. Exp Brain Res 174: 763-768.

71. Rossi A, Decchi B, Ginanneschi F (1999) Presynaptic excitability changes of group la fibres to muscle nociceptive stimulation in humans. Brain Res 818 $12-22$

72. Rossi S, della Volpe R, Ginanneschi F, Ulivelli M, Bartalini S, et al. (2003) Early somatosensory processing during tonic muscle pain in humans: relation to loss of proprioception and motor 'defensive' strategies. Clin Neurophysio 114: $1351-1358$

73. Sibley KM, Carpenter MG, Perry JC, Frank JS (2007) Effects of postural anxiety on the soleus H-reflex. Hum Mov Sci 26: 103-112.

74. Capra NF, Ro JY (2000) Experimental muscle pain produces central modulation of proprioceptive signals arising from jaw muscle spindles. Pain 86: 151-162.

75. Lihavainen K, Sipilä S, Rantanen T, Sihvonen S, Sulkava R, et al. (2010) Contribution of musculoskeletal pain to postural balance in community-dwelling people aged 75 years and older. J Gerontol A Biol Sci Med Sci 65: 990-996.

76. Pajala S, Era P, Koskenvuo M, Kaprio J, Törmäkangas T, et al. (2008) Force platform balance measures as predictors of indoor and outdoor falls in community-dwelling women aged 63-76 years. J Gerontol A Biol Sci Med Sci 63: 171-178.

77. Lamoth CJ, Daffertshofer A, Meijer OG, Lorimer Moseley G, Wuisman PI, et al. (2004) Effects of experimentally induced pain and fear of pain on trunk coordination and back muscle activity during walking. Clin Biomech (Bristol, Avon) 19: 551-563.

78. Vancleef LM, Peters ML (2006) Pain catastrophizing, but not injury/illness sensitivity or anxiety sensitivity, enhances attentional interference by pain. $J$ Pain 7: 23-30.

79. Peters ML, Vlaeyen JW, Kunnen AM (2002) Is pain-related fear a predictor of somatosensory hypervigilance in chronic low back pain patients? Behav Res Ther 40: 85-103. 
Citation: Karimi A, Saeidi M (2013) A Review of Relationship between Fear Avoidance Beliefs and Postural Stability in Non Specific Chronic Low Back Pain. J Spine 2: 139. doi:10.4172/2165-7939.1000139

Page 7 of 7

80. Levitan MN, Crippa JA, Bruno LM, Pastore DL, Freire RC, et al. (2012) Postura balance in patients with social anxiety disorder. Braz J Med Biol Res 45: 38-42.
81. Lopes FL, Azevedo TM, Imbiriba LA, Freire RC, Valença AM, et al. (2009) Freezing reaction in panic disorder patients associated with anticipatory anxiety. Depress Anxiety 26: 917-921. 